\title{
Bias Gender dalam Dakwah Thoriqoh Qodiriyah Naqsabandiyah Pondok Pesantren Suryalaya
}

\author{
Siti Sarah Sakinayati Hartati, Eunis Khoerunnisa. \\ Komunikasi Penyiaran Islam, STID Sirnarasa, Ciamis, Indonesia.
}

\begin{abstract}
ABSTRAK
Jamaah TQN PP. Suryalaya berjumlah ribuan, yang terdiri dari semua kalangan, laki-laki, perempuan, tua maupun muda, dari berbagai kesetaraan ekonomi yang berbeda, dan latar belakang pendidikan yang berbeda pula. Setiap orang harus tahu dan memahami setiap isi ajaran yang ada dalam TQN PP. Suryalaya. Selain dari Mursyid, setiap jama'ah atau murid bisa mendapatkan pesan tentang ajaran tersebut melalui para Da'i dan Da'iah yang ada di lingkungan TQN itu sendiri tanpa terkecuali. Namun fakta yang ditemukan justru tidak adanya sosok panutan seorang Da'iah yang muncul dipublik, sehingga menjadi salah satu kendala tidak tersampainya pesan tadi dengan baik khususnya kepada kalangan perempuan. Tujuannya adalah untuk mengetahui bagaimana persepsi jama'ah TQN tentang peran Da'i Perempuan dalam lingkup TQN, dan mengetahui seberapa pentingnya peran Da'i perempuan dalam kegiatan dakwah TQN PP. Suryalaya. Penelitian ini menggunakan metode penelitian kualitatif. Adapun data yang dipakai adalah dari hasil wawancara dan observasi, kisah ulama wanita terdahulu, dan sumber sumber-sumber buku yang relevan. Landasan teori yang dipakai adalah teori dakwah, dam komunikasi gender. Berdasarkan analisa data yang dilakukan, diperoleh kesimpulan bahwa adanya masalah kesenjangan gender dikalangan jama'ah TQN, yang disebabkan oleh kurang luasnya kesempatan yang diberikan kepada kaum perempuan. Dan itu mengakibatkan terjadinya rasa tidak percaya diri dikalangan akhwat. Sehingga terkadang pesan dakwah pun tidak tersampaikan dengan baik karena adanya kesenjangan tersebut. Masalah tersebut bisa diatasi
\end{abstract}


dengan adanya kesadaran semua pihak, yang harus didorong oleh kebijakan tegas dari pihak-pihak yang bertanggungjawab membuat kebijakan.

Kata Kunci : Gender; Dakwah; Thoriqoh;

\section{ABSTRACT}

TQN PP pilgrims. Suryalaya numbered in the thousands, consisting of all walks of life, men, women, young and old, from different economic equations, and different educational backgrounds. Everyone must know and understand every teaching content contained in the TQN PP. Suryalaya. Apart from the Murshid, every jama'ah or student can get messages about these teachings through the $D a^{\prime} i$ and Da'iah who are in the TQN environment without exception. However, the fact is that there is no role model of a Da'iah who appears in the public, so that it is one of the obstacles to not getting the message well, especially to women. The aim is to find out how the perceptions of the TQN jama'ah about the role of $D a^{\prime} i$ Perempuan in the scope of TQN, and to find out how important the role of $D a^{\prime} i$ women is in TQN PP da'wah activities. Suryalaya. This study used qualitative research methods. The data used are from the results of interviews and observations, stories of previous female scholars, and relevant book sources. The theoretical basis used is the theory of $d a^{\prime}$ wah, and gender communication. Based on the data analysis conducted, it was concluded that there was a gender gap problem among the TQN congregation, which was caused by the lack of opportunities given to women. And that results in a feeling of insecurity among the sisters. So that sometimes the message of $d a^{\prime}$ wah is not conveyed properly because of this gap. This problem can be overcome with the awareness of all parties, which must be encouraged by firm policies from those responsible for making policies.

Keywords: Gender; Da'wah; Thoriqoh

\section{PENDAHULUAN}

Pendahuluan Rukun agama dalam islam dibagi menjadi 3, yaitu iman, islam, dan ihsan.. Pembagian ini dengan sendirinya memunculkan kajian kajian spesifik didalamnya. Ulama dan cendekiawan Muslim sepakat merumuskannya menjadi tiga disiplin ilmu, yakni : Tauhid, Fiqih Dan 
Tassawuf. Ketiganya merupakan pengembangan dari ketiga Pilar Islam tadi (Syeikh Akbar Muhammad Fathurahman, 2016:10). Tassawuf lahir dari pengembangan keilmuan Ihsan. Tassawuf bergerak diwilayah hati. Pada kenyataanya dimensi hati menyentuh seluruh aspek keilmuan. Selanjutnya hati menjadi pententu seluruh arah ilmu. Konsekuensinya, tanpa Tassawuf seluruh ilmu menjadi hampa,tak bernilai di sisi Alloh SWT.

Seperti halnya tugas berdakwah yang disebutkan dalam berbagai teori, baik Al-Qur'an dan Sunnah, kewajiban berdakwah adalah bagi semua umat Muslim, tidak di pisahkan baik kaum laki-laki ataupun perempuan, karena keduanya memiliki kedukukan yang sama di mata Allah SWT, begitupun dalam mendakwahkan ajaran TQN yang berisikan ajaran Tassawuf sebagai salah satu hal yang pokok dalam Islam.

Pada kenyataannya, kegiatan dakwah saat ini masih didominasi oleh kaum lelaki khususnya dakwah-dakwah yang bersifat lisan. Padahal ada beberapa hal yang dirasa lebih efektif disampaikan oleh seorang perempuan, karena penyampaian dari seorang penceramah perempuan bisanya disampaikan dengan tutur kata yang lebih lembut dan santun. Apalagi, bila didaerah-daerah tertentu, kebanyakan yang sering memenuhi majelis ta'lim adalah kaum perempuan, karena banyaknya perempuan yang hanya menjadi ibu rumah tangga, yang lebih sering berada dilingkungan masyarakat dibanding laki-laki, maka acara keagamaan seperti pengajian dijadikan ajang untuk bersosialisasi menciptakan keakraban dengan lingkungan. Karena kebanyakan yang menghabiskan waktu dirumah adalah perempuan, maka bisa disimpulkan bahwa orang yang lebih punya banyak waktu untuk mendidik anakpun adalah seorang perempuan atau seorang ibu, itulah alasan mengapa seorang ibu merupakan sekolah pertama untuk anaknya.

Guru Mursyid TQN sekarang, Syeikh Muhammad Abdul Gaos Saefulloh Maslul Q.S, mendirikan Sekolah Tinggi Ilmu Dakwah Sirnarasa, tentunya dengan harapan munculnya para pendakwah baru yang bisa menjadi agen agen penyebaran TQN, dari kaum laki-laki ataupun perempuan. Sedangkan dengan belum adanya contoh sosok da'i dari kalangan 
perempuan, itu membuat kurangnya rasa percaya diri dari kalangan mahasiswi untuk tampil di depan umum dalam kegiatan apapun.

Dari pengamatan sekilas, posisi da'iah dalam dakwah TQN pun menjadi minoritas, itu terbukti dari belum adanya sosok da'i perempuan yang terlihat tampil di publik dalam kegiatan Dakwah TQN seperti kegiatan Manaqiban yang sering dilakukan oleh para jama'ah TQN. Itu membuat kurangnya rasa percaya diri dalam diri seorang perempuan untuk ikut serta dalam berbagai kegiatan yang lainnya.

Atas permasalahan diatasa penelitian ini difokuskan pada: a. Bagaimana persepsi jamaah TQN PP Suryalaya mengenai peran Da'i Perempuan sekarang?; b. Bagaimana urgensi peran da'i perempuan dalam dakwah TQN PP Suryalaya ?;. Metode penelitian yang digunakan adalah metode penelitian kualitatif. Sumber data primer dalam penelitian ini adalah beberapa orang yang mempunyai peran penting dalam dakwah dilingkungan TQN PPS Suryalaya, yaitu para jama'ah yang sudah lama menjadi jama'ah TQN PP.Suryalaya, dan para Da'i yang sudah berkiprah cukup lama di mimbar manaqib TQN PP.Suryalaya. Sumber data sekundernya adalah kepustakaan yang relevan dengan topik ini.

Studi kepustakaan digunakan untuk menghimpun data aktual dari tulisan-tulisan yang berhubungan dengan dakwah untuk menjadi bahan analisis, dan menafsirkannya secara kualitatif. Wawancara digunakan untuk menghimpun data dari jama'ah TQN PPS Suryalaya dan para Da'i sudah cukup lama berkiprah dipanggung manakib PPS Suryalaya. Diamati dari beberapa kegiatan khususnya kegiatan Manaqib yang menjadi kegiatan wajib jama'ah. Deskripsi yang mendetail tentang situasi, kegiatan, atau peristiwa maupun fenomena tertentu, baik menyangkut manusianya maupun hubungannya dengan manusia lainnya.

Dalam penelitian ini deskripsi yang disajikan berupa fenomena jarang sekali adanya sosok da'i perempuan yang muncul di ruang lingkup TQN PP.Suryalaya, diamati dari beberapa kegiatan khususnya kegiatan Manaqib yang menjadi kegiatan wajib jama'ah. 


\section{LANDASAN TEORITIS}

Webster's New World, gender diartikan sebagai "perbedaan yang tampak antara laki-laki dan perempuan dilihat dari segi nilai dan tingkah laku". Sedangkan dalam Women's Studies Encyclopedia dijelaskan bahwa gender adalah "suatu konsep kultural yang berupaya membuat pembedaan (distinction) dalam hal peran, perilaku, mentalitas dan karakteristik emosional antara laki-laki dan perempuan yang berkembang dalammasyarakat".

Beberapa definisi tentang gender yang akan diungkapkan dibawah ini dapat dikatakan bahwa gender merupakan jenis kelamin sosial, yang tentunya berbeda dengan jenis kelamin dalam pengertian biologis. Dikatakan jenis kelamin sosial karena merupakan suatu keadaan yang telah melekat pada masyarakat yang sudah membudaya dan norma sosial masyarakat yang diberikan pada kaum laki-laki dan perempuan dan tentu adanya pembedakan antara peran jenis kelamin lakilaki dan perempuan. "Gender merujuk pada peranan dan tanggung jawab laki-laki dan perempuan yang diciptakan dalam keluarga, masyarakat dan budaya"(UNESCO, 2007). Pemahaman konsep gender menurut HT.Wilson (1998) yang memandang gender sebagai "suatu dasar untuk menentukan perbedaan sumbangan laki-laki dan perempuan pada kebudayaan dan kehidupan kolektif yang sebagai akibatnya mereka menjadi laki-laki dan perempuan".

Sementara Mansour Fakih (2008:8) mengarttikan gender sebagai "suatu sifat yang melekat pada kaum laki-laki maupun perempuan yang dikonstruksi secara sosial maupun kultural". Dalam hal ini Gender dipersoalkan karena secara sosial telah melahirkan perbedaan peran, tanggung jawab, hak dan fungsi serta ruang aktivitas laki-laki dan perempuan dalam masyarakat. Perbedaan tersebut akhirnya membuat masyarakat cenderung diskriminatif dan pilih-pilih perlakuan akan akses, partisipasi, serta kontrol dalam hasil pembangunan laki-laki dan perempuan. 
Sebelum membahas teori komunikasi gender, penulis akan membahas teori komunikasi umum terlebih dahulu. Yaitu teori komunikasi Harold Laswell, dia menjelaskan bahwa pada dasarnya komunikasi itu menyangkut lima pertanyaan sederhana, yaitu :

Who? / siapa / komunikator

Say What / mengatakan apa / pesan

In Which Channel / melalui saluran apa / media

To Whom ( kepada siapa )/ khalayak / komunikan

With What Effect / dengan akibat atau efek apa

Model Laswell ini menunjukan bahwa pihak pengirim pesan atau komunikator mempunyai suatu keinginan atau tujuan untuk mempengaruhi pihak penerima pesan atau komunikan, karenanya komunikasi harus dipandang sebagai upaya persuasif(Dzikry Fachrul Nurhadi, 2017:76). Dalam proses komunikasi pun terdapat beberapa hambatan, salah satunya adalah perbedaan gender.

Komunikasi gender memfokuskan pada deskripsi dan analisis terhadap berbagai bentuk ketimpangan gender yang ada di dunia komunikasi, termasuk hal-hal dibalik layar yang dianggap sebagai anteseden bagi terbentuknya produk-produk komunikasi yang bias gender tersebut. Adapun teori yang relevan adalah Genderlect Styles (Deborah Tannen)

Deborah Tannen dalam Griffin $(433 ; 2012)$ mengaitkan pembicaraan Genderlect Style terkait gaya bicara perempuan dan laki-laki. Gaya bicara seseorang biasanya dikaitkan dengan sisi maskulinitas dan feminitas. Tannen melihat beberapa hal yang berbeda antara perempuan dan lakilaki. Perempuan mencari hubungan VS laki-laki mencari status Pembicaaran terkait hubungan Vs pembacaan laporan. Tannen menyebutkan tiga syarat dalam percakapan lelaki (433:2012) yaitu : a. Pria berkomunikasi untuk menegaskan ide, pendapat, dan identitasnya. B. Pria berbicara untuk memecahkan masalah atau mengembangkan strategi. C. Pria berbicara dengan cara membuat orang tertarik pada dirinya. 
Hal yang berbeda yang dilakukan perempuan yaitu : a. Perempuan berbicara untuk menciptakan dan memelihara hubungan. B. Perempuan senang melibatkan orang lain dalam percakapan mereka dan mereka butuh untuk ditanggap. C. Perempuan harus menunjukkan kepekaan mereka terhadap orang lain dan juga dalam sebuah hubungan. Ada hal yang juga patut dipertimbangkan dalam sebuah pembicaraan. Perempuan sangat menghargai pembicaraan yang baik, sementara pria menghargai laporan bicara.

Menurut Mansour Faqih ada beberapa maninfestasi ketidakadilan gender dalam masyarakat diantaranya :

- Marginalisasi, ada beberapa jenis, bentuk, tempat, waktu, dan mekanisme proses marginalisasi kaum perempuan disebabkan oleh perbedaan gender tersebut(Yayah Nurhidayah, Eti Nurhayati, 2018:118. “Dari segi sumbernya marginalisasi perempuan dapat berasal dari kebijakan pemerintah, keyakinan, dan tafsiran agama, keyakinan tradisi, dan kebiasaan, atau bahkan asumsiilmu pengetahuan" ( Mansour Fakih, 1999: 13-14).

- Subordinasi, anggapan bahwa perempuan makhluk irrasional dan emosional sehingga tidak mampu tampil menjadi pemimpin, berdampak munculnya sikap yang menempatkan perempuan pada posisi tidak penting dan hanya sebagai pelengkap (objek).

- Stereotip, secara umum stereotype adalah pelabelan negatif atau penandaan terhadap suatu kelompok tertentu dan selalu menimbulkan ketidakadilan. Salah satu jenis stereotype yang bersumber dari perbedaan gender, misalnya penandaan yang berawal dari asumsi bahwa perempuan bersolek adalah dalam rangka memancing perhatian lawan jenisnya, maka setiap ada kasus kekerasan atau pelecehan seksual selalu dikaitkan dengan stereotype ini(Mansour Fakih, 1999: 16-17).

Secara bahasa perkataan dakwah memiliki beberapa arti yang di antaranya adalah sebagai berikut: Memanggil, dikatakan dalam bahasa Arab (دعا فلان فلانا) "sipulan memanggil sipulan"; 
Secara istilah dakwah adalah menyampaikan agama Allah dan menyebarkannya dan menunjukkan manusia kepada suatu perbuatan yang akan membawa kepada kebaikan bagi kehidupan dunia dan akhirat serta menerapkan syariat dengan penuh toleransi. Ibnu Taimiyah seperti yang dikutif oleh Muhammad Sa'id Mubarak memberikan definisi dakwah sebagai "menyeru manusia agar beriman kepada Allah, meyakini dan membenarkan apa-apa yang diberitahukan oleh para Rasul serta mentaati segala perintah-Nya" (Mubarak, 2005: 15).

Landasan dakwah Islam adalah Al-Qur'an dan Hadits. Pertama Di antara nash-nash yang menunjukkan hal tersebut dan dijadikan landasan dakwah adalah Q.S Ali Imran (2: 104): “Dan hendaklah ada di antara kamu segolongan umat yang menyeru kepada kebajikan, menyuruh kepada yang ma'ruf dan mencegah dari yang munkar, merekalah orangorang yang beruntung" (Soenarjo dkk., 1971: 93).

Ayat di atas menunjukkan bahwa dakwah adalah sebuah kewajiban ditunjukkan dengan digunakannya lam amr pada kata ولنكن, walaupun demikian pada saat di antara umat Islam yang melakukannya maka hukumnya digeser menjadi fardhu kifayah, hal ini ditunjukkan dengan kata منكم

Kedua Di antara Hadits yang berhubungan dengan kewajiban berdakwah adalah Hadits yang diriwayatkan oleh Imam Muslim sebagai berikut (Muslim, Juz I: 168, Hadits No. 71).

"Telah menceritakan kepadaku Umar al-Naqid dan Abu Bakar ibn al-Nadr dan Abdu Ibnu Humaid dan redaksinya milik Abdu, mereka berkata: telah menceritakan kepada kami Ya'kub ibn Ibrahim ibn Sa'ad dia berkata: telah bercerita kepadaku ayahku dari Shalih Ibnu Kaisan dari al-Harits dari Ja'far ibn Abdullah ibn al-Hakam dari Abdirrahman al-Miswar dari Abi Rafi dari Abdillah bin Mas'ud sesungguhnya Rasulullah Saw. telah bersabda: "Tidak ada seorang Nabi pun yang diutus oleh Allah kepada suatu umat sebelumku, kecuali ada sekelompok umat yang menjadi hawari (sahabat/penolong) dan sahabat yang berpegang teguh pada sunnah-sunnahnya dan selalu mengikuti perintah-perintahnya kemudian muncul generasi setelah mereka yang berkata atas apa yang tidak mereka kerjakan dan melakukan perbuatan- 
SSS. Hartati, E. Khoerunnisa

perbuatan yang tidak diperintahkan. Maka barangsiapa yang berjihad dengan tangannya maka ia adalah orang ynag beriman dan barangsiapa yang berjihad dengan hatinya maka ia adalah seorang yang beriman, dan barangsiapa yang tidak melakukan salah satu dari hal-hal tersebut maka berarti dalam dirinya tidak terdapat keimanan walaupun sebesar biji sawi."(HR. Muslim).

Tujuan dakwah terbagi dua, yaitu: Tujuan dakwah secara umum (major objective), merupakan sesuatu yang hendak dicapai dalam seluruh aktivitas dakwah. Tujuan umum ini adalah mengajak umat manusia (meliputi Muslim dan non muslim) kepada jalan yang benar dan diridhai oleh Allah SWT, agar mendapatkan kebahagiaan di dunia dan di akhirat; Tujuan dakwah secara khusus (minor objective) merupakan perumusan tujuan sebagai perincian daripada tujuan umum dakwah. Oleh karena itu dibawah ini disajikan beberapa tujuan khusus dakwah, antara lain adalah: a. Mengajak manusia yang sudah memeluk Islam untuk selalu meningkatkan ketaqwaannya kepada Allah SWT;. B. Membina mental agama Islam bagi kaum yang sudah mukallaf;. C. Mengajak manusia yang belum beriman kepada Allah SWT (memeluk agama Islam); d. Mendidik anak-anak agar tidak menyimpang dari fitrahnya.

Sebagai landasan bahan berfikir, penulis mengambil sebuah kisah wali perempuan pada zaman dulu, yaitu kisah cicit perempuan Rosululloh yakni Sayyidah Nafisah. Berikut adalah kisah tentang perempuan suci dan mulia, cicit dari Nabi Muhammad SAW, Rasulullah. Beliau ialah Sayyidah Nafisah binti Hasan al-Anwar bin Zaid bin Hasan bin Ali bin Abi Talib, yang merupakan menantu Rasulullah SAW. Beliau sangat menyerupai bibinya yang bernama Sukainah al-Kubra binti Zaidbin Hasan bin Ali bin Abi Talib.

Sejak kecil, Sayyidah Nafisah sudah hafal Al-Qur'an. Iajuga sangat memahami bahwa Nabi Ibrahim adalah bapak moneteisme sejati, sekaligus bapak Rasulullah lewat jalur Nabi Ismail yang merupakan keturunan Nabi Ibrahim. Sedangkan Sayyidah Nafisah sendiri adalah cicit, keturunan dari Rasulullah. 
Ketika dirinya berusia 44 tahun, ia tiba di Kairo pada 26 Ramadhan 193 H. Kabar kedatangan perempuan yang luar biasa ini telah menyebar luas. Ia pun disambut oleh penduduk Kairo yang merasa bersyukur didatangi oleh Sayyidah Nafisah. Ratusan orang tiap hari datang hendak menemuinya. Dari mulai berkonsultasi, meminta doa ataupun mendengar nasihat dan ilmu darinya.

Kemudian, al-Syafi'i meminta bertemu dengannya di rumahnya. Sayidah Nafisah menyambutnya dengan seluruh kehangatan dan kegembiraan. Pertemuan itu dilanjutkan dengan pertemuan-pertemuan yang sering diadakan ke depannya. Masing-masing saling mengagumi tingkat intelektualitasnya.

Saat itu, diketahui jika Imam al-Syafi'i berangkat untuk mengajar di Masjidnya di Fustat, ia mampir ke rumah Sayyidah Nafisah. Begitu juga ketika pulang kembali ke rumahnya. Dikabarkan bahwa Imam al-Syafi'i adalah ulama yang paling sering bersama Sayyidah Nafisah dan mengaji kepadanya, justru dalam status Imam al-Syafi'i sebagai tokoh besar dalam bidang usul al-fiqh dan fiqh.

Menurut KH. Husein Muhammad, di antara nasihat Sayyidah Nafisah kepada para muridnya adalah: a) Jika kalian ingin berkecukupan, tidak menjadi miskin, bacalah QS. al-Waqi'ah. B). Jika kalian ingin tetap dalam keimanan Islam, bacalah QS. al-Mulk. C). Jika kalian ingin tidak kehausan pada hari dikumpulkan di akhirat, bacalah QS. al-Fatihah. D). Jika kalian ingin minum air telaga Nabi di akhirat, maka bacalah QS. al-Kautsar.

Dari kisah Sayyidah Nafisah, penulis menarik kesimpulan bahwa seorang perempuan pun layak untuk menjadi panutan umat, ketika terbekali dengan ilmu dan amal yang baik. Bukan hanya bisa berdakwah dalam keluarga ataupun terhadap sesama perempuan, tapi dikhalayak umum untuk semua kalangan. Dan Sayyidah Nafisah merupakan fakta sejarah bahwa seorang perempuan bisa menjadi seorang ulama tersohor, bahkan menjadi guru bagi seorang Imam Syafi'i. Selain Nafisah terdapat banyak perempuan hebat yang bisa berdakwah, juga menjadi panutan umat, baik dari kalangan perempuan sufi ataupun bukan sufi. 


\section{HASIL DAN PEMBAHASAN}

Tidak ada sosok Da'i Perempuan dalam setiap kegiatan besar dan rutin jama'ah TQN. Begitu banyaknya jama'ah TQN dari berbagai kalangan, yang terdiri dari jama' ah laki-laki dan perempuan, tidak pernah ada sosok Da'i perempuan yang muncul dalam panggung Manaqib. Menurut Abah Aos, memang Abah tidak pernah menunjuk seorang perempuan untuk naik keatas panggung Manaqib Pusat, karena tidak pernah ada contohnya dari jaman Abah Anom (Wawancara dengan Abah Aos tanggal 20 April 2019 pkl 09.28). Namun itu bukan berarti Abah tidak memberikan kesempatan kepada kaum peremuan untuk berkiprah menjadi Da'i, kalau untuk Manaqib di Madrasah daerah, dirumah atau tempat lainnya, kata abah "silahkan saja, bahkan Abah sangat mengharapkan dan senang apabila banyak bibit bibit Da'i perempuan yang muncul, karena perintah Dakwah dalam Q.S An-Nahl ayat 125 pun, perintah untuk menyeru atau berdakwah itu bukan ditujukan kepada laki-laki saja, tapi kepada semua".

Dalam wawancara dengan Abah, Abah menyebutkan bahwa dulu ketika jaman Abah Anom, ada istri Abah yaitu Umi Rosliani Hasnah yang kiprah dalam dunia Dakwah TQN nya begitu membanggakan. Dulu, ketika Abah sibuk diatas panggung ke berbagai daerah, Umi pun tidak diam dirumah, terkadang ketika ada undangan yang tidak bisa Abah hadiri, Abah wakilkan ke Umi, dan materi yang disampaikan oleh Umi pun sama dengan apa yang biasa Abah sampaikan, yaitu tentang Dzikir, Tassawuf, dan Thoriqoh. Menurut Abah Aos, Umi merupakan salah satu jimat kebanggaan Abah Anom, karena Umi merupakan salah satu pejuang dalam Dakwah TQN, terutama dalam menyebarkan metode Dzikir dalam penyembuhan Narkotika.

Kini, Abah juga menginginkan para jama'ah TQN lainnya bisa termotivasi, dan mencontoh perjuangan Umi Rosliani Hasnah dalam berjuang mendakwahkan TQN. Itulah salah satu alasan Abah mendirikan Sekolah Tinggi Ilmu Dakwah Sirnarasa, Abah ingin mencetak bibit - bibit Da'i dan Da'iyah unggul untuk membantu menjaga dan menyebarkan ajaran Tassawuf TQN PP.Suryalaya. 
Karena tidak adanya sosok perempuan yang ditampilkan dalam kegiatan Manaqib pusat di Sirnarasa, menurut beberapa Narasumber, itulah yang menjadi alasan mengapa di Manaqib lainnya pun, jarang yang menampilkan sosok perempuan dalam kegiatan Manaqib atau kegiatan TQN lainnya di berbagai daerah dan berbagai kesempatan.

Tidak Adanya Kesempatan menimbulkan Kesenjangan Gender. Hasil dari wawancara berbagai sumber, ada beberapa pendapat yang menyatakan bahwa tidak adanya sosok Da'i perempuan yang muncul di TQN, disebabkan karena tidak adanya kesempatan yang diberikan. Itu menjadikan kepercayaan diri perempuan di ruang lingkup TQN menjadi rendah. Hal seperti itu menjadikan adanya permasalahan kesenjangan gender di ruang lingkup TQN. Adapun beberapa perempuan di TQN yang menjadi seorang Da'iyah seperti Bu Hj Lilis Siti Sa'adah, kiprahnya tetap di luar lingkup TQN, bahkan jarang materi yang disampaikan itu mengandung materi tentang TQN. Namun beliau berharap diberikan kesempatan untuk berkiprah di ruang lingkup TQN, agar beliau pun percaya diri ketika berdakwah diluar. Bunda Witrin juga merupakan Da'i perempuan dari kalangan TQN, akan tetapi lebih sering tampil diluar lingkup TQN daripada kegiatan TQN misalnya di Manakib.

Dalam kegiatan dakwah TQN, khususnya yang besifat verbal, ketika seorang perempuan mendengarkan sesama perempuan berdiri di depan dan memberikan ceramah, ada rasa bangga tersendiri ketika melihat ada sosok perempuan didepan yang mewakili perempuan lainnya untuk berbicara dan menyampaikan aspirasinya(Wawancara bersama $\mathrm{Hj}$. Enong Mustaqimah tgl 15 Agustus 2019 pkl 14.27).

Selain pendapat dari kaum perempuan, penulis pun mewawancarai beberapa Da'i laki-laki tentang bagaimana tanggapan mereka mengenai pentingnya peran Da'i perempuan dalam kegiatan dakwah TQN. Dalam menyampaikan materi, seorang Da'i laki-laki merasa ada kecanggungan ketika materi yang disampaikan berkenaan dengan bab Fiqih seorang perempuan, tidak bisa gamblang begitu saja dalam menyampaikan karena bukan seorang pelaku sesungguhnya(Wawancara dengan KH.Didin Solehudin tgl 15 Agustus 2019 pkl 15.17). 
Adanya kebijakan yang menyeluruh untuk mewadahi kaum perempuan, akan menjadi salah satu solusi problematika kesenjangan gender ini. Artinya, perlu adanya perhatian khusus dalam menunjang pendidikan seorang perempuan, termasuk dalam ruang lingkup TQN, karena perempuan pun memiliki banyak peran dakwah yang harus dipenuhi.

\section{PENUTUP}

Berdasarkan hasil penelitian dan pembahasan, dapat disimpulkan menjadi 2 poin untuk menjawab Rumusan Masalah Penelitian. Persepsi jama'ah TQN mengenai peran Da'i perempuan sekarang di ruang lingkup TQN, memang sangat jarang, bahkan bisa dibilang tidak ada, dilihat dari kegiatan besar rutinan yang biasa dilakukan jama'ah TQN, para jama'ah jarang melihat adanya sosok perempuan yang muncul, itu menyebabkan tidak adanya motivasi kepada jama'ah perempuan untuk berkiprah dalam dunia dakwah TQN.

Para jama'ah perempuan merasa adanya kesenjangan gender dalam ruang lingkup TQN, dengan adanya fakta bahwa jarangnya kesempatan yang diberikan kepada kaum perempuan untuk tampil di ruang publik.

Itupun menjadi salah satu kebingungan bagi para Mahasiswi Sekolah Tinggi Ilmu Dakwah Sirnarasa dikala melihat tidak adanya contoh sosok Da'i perempuan untuk dijadikan contoh mereka baik selama menjadi Mahasiswi ataupun setelah menjadi lulusan.

Urgensi Peran Da'i perempuan dalam kegiatan dakwah TQN, sama pentingnya seperti Da'i laki - laki, bahkan sangat dibutuhkan, karena majelis - majelis pengajian baik di ruang lingkup TQN ataupun tidak, kebanyakan diramaikan oleh perempuan alias ibu - ibu. Itu dikarenakan perempuan kebanyakan lebih mempunyai waktu luang di lingkungan sosial masyarakat. Dan peran seorang Da'i perempuan dirasa sangat diperlukan ketika keharusan penyampaian materi tentang Bab Fiqih perempuan, dikarenakan akan dirasa kurang efektif bila yang menyampaikan bukan sesama perempuan 


\section{DAFTAR PUSTAKA}

Abdul Wahab, Muhbib, dan Abdurrahman Saleh. 2004. Psikologi Suatu Pengantar dalam Perspektif Islam. Jakarta. : Kencana.

Asmaya, Enung. 2003. Aa Gym Da'i Sejuk dalam Masyarakat Majemuk. Jakarta : Mizan Publika.

Aziz, Moh. Ali. 2004. Ilmu Dakwah. Jakarta : Kencana Prenada Media Danim, Sudarwan. 2002 .Menjadi Peneliti Kualitatif: Ancangan Metodologi, Presentasi, dan Publikasi Hasil Penelitian Untuk Mahasiswa dan Penelitian Bidang Ilmu-Ilmu Sosial, Pendidikan, dan Humaniora, Bandung : CV.Pustaka Setia.

Daymond, C dan Holloway, Immy.2008. Metode-Metode Riset Kualitatif dalam Public Relation dan Management Comunication, terj. Cahya W. Yogyakarta: Bentang.

Dhofier, Zamakhsyari. Tradisi Pesantren Studi Tentang Pandangan Hidup Kiyai.

Jakarta : LP3ES.

Fachrul Nurhadi, Dzikry. 2017. Teori Komunikasi Temporer. Depok : KENCANA

Ilahi, Wahyu. 2010. Komunikasi Dakwah. Bandung : PT. Remaja Rosda Karya

Ilahi, Wahyu dan Muhammad Munir. 2009. Menejemen Dakwah. Jakarta : Kencana

Masyari, Anwar. 1981. Studi Tentang Ilmu Dakwah. Surabaya : Bina Ilmu. Muhammad Fathurahman, Akbar. 2016. Jalan Menuju Tuhan : Memahami dan Mengamalkan Islam secara Komprehensif dan Terpadu. Jakarta : Grasindo.

Mulyana, Dedi. 1996. Pengantar Ilmu Komunikasi. PT. Remaja Rosda Karya. Munir, Muhammad. 2009. Metode Dakwah. Jakarta. Kencana

Nasution, Harun, 1990. Thoriqot Qodiriyyah Naqsyabandiyyah. Tasikmalaya : Institut Islam Latifah Mubarokiyyah.

Nasution, Harun. 1982. Akal Dan Wahyu dalam Islam. Jakarta : Universitas Indonesia. 